\title{
IMPROVISACIÓN MUSICAL Y DISCURSO LITERARIO EN JULIO CORTÁZAR
}

\author{
POR \\ EDUARDO SOREN TRIFF \\ University of Miami
}

A partir de $E l$ perseguidor (1959), el jazz cobra una importancia destacada en la obra de Julio Cortázar a diversos niveles de interpretación literaria. Si en el texto mencionado se utilizó como base para la persecución, dentro de la realidad concreta de otra realidad intersticial, en Rayuela (1963), el autor ensaya la improvisación jazzística como forma de acercarse a la autenticidad a través de formas discursivas determinadas. Este trabajo percibe el azar como punto de unión entre un lenguaje auténtico y la improvisación musical, observa la existencia de una actitud artística paralela en el improvisador de jazz y el escritor, y adapta un modelo de improvisación musical al análisis de modos discursivos en Rayuela.

Existe en la obra de Cortázar una necesidad de encontrar un orden que le permita identificarse con una realidad más allá de lo tangible. En esta búsqueda de una comunicación interior, tropieza con un lenguaje incapaz de comunicar contenidos auténticos (Rayuela 505, Genover 65, Harss 288), y toma una actitud radical frente al mismo en la que el azar, visto aquí como elemento de indagación de lo auténtico en el que no interviene la razón - o lo hace a un nivel mínimo-, es la clave de todo juego textual (Picon 139), y de la improvisación en cuanto proceso espontáneo e intuitivo más que metódico y racional (Gioia 55).

La expresión del especialista Hinrich Hudde de que Cortázar “... asocia la improvisación del jazz a la 'escritura automática' de los surrealistas”(40), es cierta en relación al azar'. Cortázar vincula la improvisación con el lenguaje auténtico desde $E l$ perseguidor, donde Bruno, el crítico, dice del músico Johnny Carter:

la renuncia a la satisfacción inmediata indujo a Johnny a elaborar un lenguaje que él y otros músicos están llevando hoy a sus últimas posibilidades. Este jazz desecha todo erotismo fácil, todo wagnerianismo por decirlo ası, para situarse

\footnotetext{
${ }^{1}$ En este aspecto se debe agregar que Cortázar está de acuerdo sólo en principio, porque considera los experimentos surrealistas insuficientes. Propone ir más allá de la escritura automática y la asociación libre de palabras. Ver Rayuela 499 y 505.
} 
en un plano aparentemente desasido donde la música queda en absoluta libertad... una música que me gustaría llamar metafísica, Johnny parece contar con ella para explorarse, para morder en la realidad que se le escapa todos los días. Veo ahíla alta paradoja de su estilo, su agresiva eficacia (313).

Plantea la teoria de una música - un lenguaje- "en absoluta libertad" como herramienta de exploración del ser; utiliza la improvisación como instrumento cognoscitivo, dejando de lado lo fácilmente humano (la realidad cotidiana, la cultura establecida, el lenguaje heredado) para perseguir un nivel más profundo. Esta búsqueda se mantiene en sus novelas posteriores.

Cortázar reconoce la existencia de la vinculación entre improvisación musical y su obra en La vuelta al día en ochenta mundos (1967):

A mi tocayo [Jules Verne] le debo el título de este libro y a Lester Young la libertad de alterarlo... Una noche en que Lester llenaba de humo y lluvia la melodía de "Three little words", sentí más que nunca lo que hace a los grandes del jazz, esa invencion que sigue siendo fiel al tema que combate y transforma e irisa (7).

\section{Y seguidamente:}

Sucede además que por el jazz salgo siempre a lo abierto, me libro del cangrejo de lo idéntico para ganar esponja y simultaneidad porosa, una participación que en esa noche de Lester era un ir y venir de pedazos de estrellas, de anagramas y palindromas que en algún momento me trajeron inexplicablemente el recuerdo de mi tocayo y de golpe ... fue la vuelta al día en ochenta mundos porque a mí me funciona la analogía como a Lester el esquema melódico (7).

Cortázar, escuchando a Lester Young, comenta cómo forma el discurso musical a base de frases que se contraponen para sostenerse a sí mismas (contraste y analogía) y prolongar la línea improvisativa. Asimismo, reconoce que a través de la improvisación recobra su libertad expresiva y se siente receptivo y más pleno, confiesa que a través de la analogía construye su discurso poético, de la misma manera que Lester Young el musical.

Para adaptar un modo de producción musical a otro literario deben contemplarse algunos factores asociados a la composición y ejecución en ambos medios artísticos. Ted Gioia establece la diferencia básica entre la música escrita y la creada por el jazz al hecho de que la última es espontánea, y en ella se unen ejecutante y compositor sin necesidad de la mediación de la música escrita (Gioia 33). Joseph Riposo presenta la base fisiológica de dicho proceso cuando menciona la asociación de la improvisación y la lectura musical a cada uno de los hemisferios cerebrales (28-30): mientras el izquierdo realiza la parte analítica - la lectura-, el derecho no funciona por asociaciones lógicas, sino por la evaluación de imágenes y emociones. La improvisación es, según Riposo, una actividad musical del hemisferio derecho. Cuando lo anterior se aplica a la 
literatura se presenta la dificultad de que el escritor es convencionalmente un "compositor," es decir, produce su obra a un nivel racional, escrita mediante signos; por lo tanto, el escritor que desee reproducir el fluir improvisativo necesita un lenguaje y una organización lingüística diferentes. Esta situación coincide con el interés de Cortázar por un lenguaje nuevo, la cual no parece tan absurda si se lee el comentario de Riposo sobre Bob Samples y los indios hopi:

He relates that in Hopi people, because of their symbolic language, more right hemisphere activity seemed to be present that would be if the English language were spoken. I found this to be an interesting parallel to improvisation ... although the Hopi language has structure and grammar, it seems to possess several qualities different from English ... (77).

En otras palabras, existe concretamente un lenguaje con esas características y está asociado por especialistas a la improvisación musical.

Debe tenerse en cuenta también que aunque la actitud inicial del artista ante el acto creador pueda ser la misma, el material del músico es el sonido, producido mediante un movimiento motor efectuado sobre un instrumento u órgano fisiológico, en un tiempo determinado, mientras el lenguaje escrito utiliza la palabra (cargada de un contenido heredado), y unas reglas del lenguaje más difíciles de romper que las musicales. El ejercicio motor, sin embargo, no es importante en el desarrollo del discurso textual ni tampoco el tiempo, pues el texto puede realizarse sin límite temporal y retocarse lo escrito ${ }^{2}$. Cuando se habla entonces de influencia de la improvisación musical en el texto no se hace referencia al acto mismo de improvisar, sino al producto final, sabiendo que mientras el acto musical va a descansar en gran medida en las habilidades motoras, el de la escritura va a estar apoyado en un intenso proceso asociativo que depende más de la conexión entre palabra, literatura, la memoria y otras fuentes de conocimiento.

El modelo propuesto por Jeff Pressing en "Improvisation: Methods and Models" es adecuado a los propósitos de este trabajo. Se observará especialmente la producción de un texto determinado, cuya representación cognoscitiva se evalúa como literatura, y el siguiente proceso cognoscitivo que, basado en el sistema nervioso central, genera el diseño de la próxima secuencia de acción (textual) y la realiza (Pressing 130).

En el proceso de improvisación que describe Pressing es fundamental el "feedback", mediante el cual se corrigen los errores, se cierran las diferencias entre la música o texto que se intenta hacer y la que realmente se hace o escribe, y puede servir de motivo o base para la continuidad -musical o textual (135).

\footnotetext{
${ }^{2}$ Gioia menciona la posibilidad de la aplicación de los principios de la improvisación a otras artes, pero sin mucha conviccion. Cita el caso de Jack Kerouac y su novela On the Road, de la cual dijo Truman Capote: "It is not writing, it is typing." (Gioia 61).
} 
El "feedforward" (136), por otra parte, es aquel elemento que contiene en sí la capacidad de anticipación que garantizará la continuidad.

El modelo describe la improvisación como una secuencia de secciones. A cada sección la llama "event cluster", es decir, un grupo de sucesos musicales, que denomina con la letra $E$. Así, improvisación, I, es simplemente una cadena de "event clusters", que en este análisis se llamarán también motivos textuales $\left(I=\left\{E_{1}, E_{2} \ldots E_{n}\right\}\right)$.

La continuidad textual $\left(E_{i+1}\right)$ se genera sobre la base de sucesos anteriores $\left(\left\{\mathrm{E}_{1}, \mathrm{E}_{2}, \ldots \mathrm{E}_{\mathrm{i}}\right\}=\{\mathrm{E}\}_{\mathrm{i}}\right)$, el referente $(\mathrm{R})$, que representa los elementos literarios de referencia, la meta $(G)$, y la memoria $(M)$-que recoge el conjunto de la experiencia vital del escritor-, dando por resultado que un motivo textual intermedio cualquiera será generado por el conjunto de motivos textuales anteriores, la referencia literaria de que disponga el escritor, la meta que concibe y su experiencia, conocimientos y emociones contenidos en la memoria $\left([(E), R, G, M] \rightarrow E_{i+1}\right.$.

El motivo textual intermedio $\left(E_{\mathfrak{i}}\right)$ está representado por aspectos que llevan en sí mismos posibilidades para crear variantes, siendo en el caso de la escritura la visión gráfica del texto, el sentido literario, y otros aspectos culturales que puedan afectar el escrito. Estos aspectos se descomponen en objeto o signos gráficos del lenguaje, significado literario, y procesos de cambio $(\mathrm{O}, \mathrm{S}, \mathrm{P})$, respectivamente. Cada aspecto está integralmente compuesto de una parte objetiva, una subjetiva y una posibilidad de transformación, que influyen en el generador de las variantes textuales. El generador funciona a base de asociaciones por analogia o contraste, y es afectado también por el referente, las metas, la memoria y el texto anterior $\left(\mathrm{E}_{\mathrm{i}-1}\right)$ al motivo intermedio $\left(\mathrm{E}_{\mathrm{i}}\right)$. El cuadro siguiente es una interpretación del propuesto por Pressing (160):

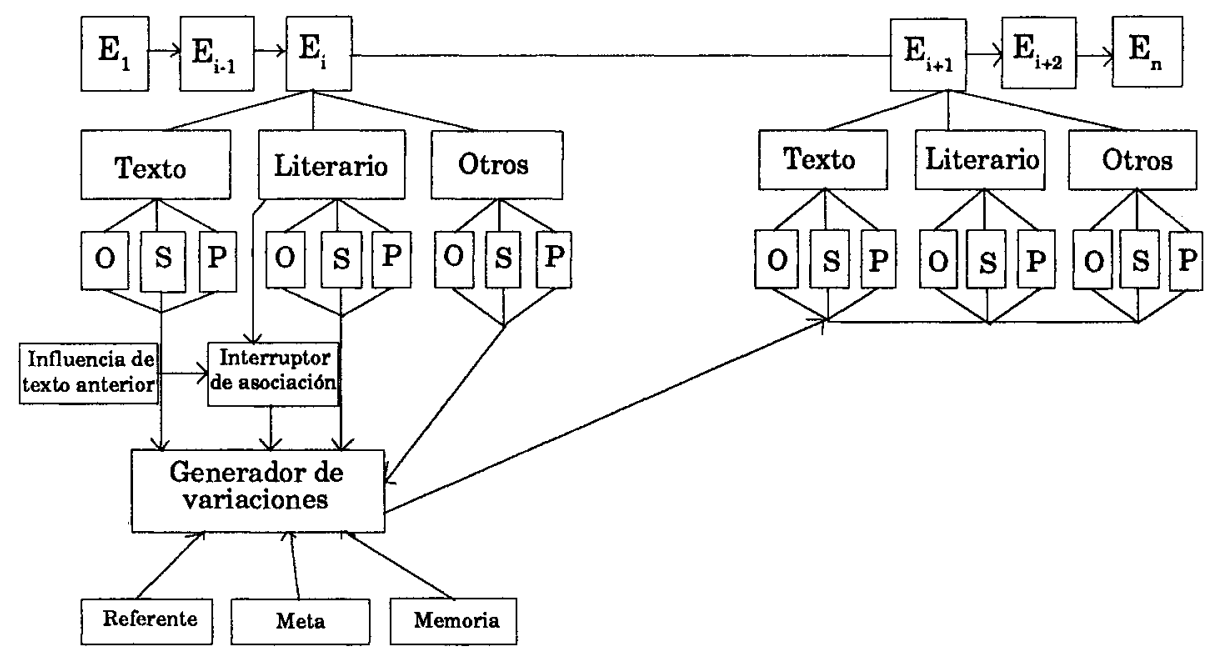


El texto que se analizará pertenece al capítulo 47 de Rayuela (328-29); es un monólogo interior controlado que se ha fragmentado en cuatro partes, subdivididas a su vez en motivos textuales para facilitar su observación.

Primer fragmento:
(Tema A)
$\mathrm{E}_{1}$
Soy yo, soy él. Somos, pero soy yo, primeramente soy yo, defenderé ser yo hasta que no pueda más, Atalía, soy yo. Ego. Yo. Diplomada, argentina, una uña
$\mathrm{E}_{3}$ encarnada, bonita de a ratos, grandes ojos oscuros, yo. Yo. Yo-yo, carretel y piolincito. Cómico.

Los tres motivos anteriores, tienen la influencia del texto anterior (los capítulos precedentes y la creación del personaje Atalía). El texto "soy yo" del motivo primero se reelabora en el segundo y tercer motivo de esta manera: "soy yo", "yo", "yo-yo". El texto concreto ha sido sensible a un proceso de cambio gráfico y significativo, que convierten la autoafirmación de Atalía en un juguete infantil.

Segundo fragmento:

$\begin{array}{ll}\text { (Tema B) } & \text { Manú, qué loco, irse a Casa América y solamente por } \\ \mathrm{E}_{4} & \text { divertirse y alquilar este artefacto. } \\ \mathrm{E}_{5} & \text { "Rewind." Qué voz, ésta no es mi voz. Falsa y forzada: "Soy } \\ & \begin{array}{l}\text { yo, soy el. Somos, pero soy yo, primeramente soy yo, } \\ \text { defenderé ..." }\end{array} \\ & \begin{array}{l}\text { "Stop." Un aparato extraordinario, pero no sirve para pensar } \\ \text { en voz alta, o a lo mejor hay que acostumbrarse, Manú } \\ \text { habla de grabar su famosa pieza de radioteatro sobre las } \\ \text { señoras, no va a hacer nada. }\end{array}\end{array}$

La asociación entre el motivo $\mathrm{E}_{3}$ y $\mathrm{E}_{4}$ se produce ahora por el contraste TalitaManú; el generador de variantes recurre a la influencia del texto anterior y presenta el personaje Manú junto a la grabadora que funcionará como "feedforward", pues se adelanta un elemento textual que tiene la capacidad de servir de base para la creación de los siguientes motivos textuales. En $\mathrm{E}_{4}$ se le llama "este artefacto," en $\mathrm{E}_{5}$ se reproduce lo que ha sido grabado, y en $\mathrm{E}_{6}$ "un aparato extraordinario" que ofrece información argumental (la obra de radioteatro que Manú desea grabar).

Tercer fragmento:

$\begin{array}{ll}\text { (Tema C) } & \begin{array}{l}\text { El ojo mágico es realmente mágico, las estrías verdes } \\ \text { que oscilan, gato tuerto mirándome. Mejor taparlo con un } \\ \mathrm{E}_{7}\end{array} \\ \begin{array}{l}\text { cartoncito. } \\ \mathrm{E}_{8}\end{array} & \begin{array}{l}\text { Rewind. La cinta corre tan lisa, tan parejita. Volume. } \\ \text { Poner en } 5 \text { o } 51 / 2: \text { "El ojo mágico es realmente mágico, las } \\ \text { estrías verdes que os..." }\end{array} \\ \mathrm{E}_{9} & \begin{array}{l}\text { Pero lo verdaderamente mágico sería que mi voz dijese: "El } \\ \text { ojo mágico juega a la escondida, las estrías rojas..." }\end{array}\end{array}$




$\begin{array}{ll} & \text { Demasiado eco, hay que poner el micrófono } \\ & \text { más cerca y bajar el volumen. } \\ \text { (Puente) } & \text { Soy yo, soy él. Lo que realmente soy es una parodia de } \\ \mathrm{E}_{10} & \text { Faulkner. Efectos fáciles. }\end{array}$

En los motivos anteriores, la grabadora se presenta como influencia del texto anterior y "feedback" en el que se basan los motivos textuales siguientes: "el ojo mágico es realmente mágico" en el motivo siete $\left(\mathrm{E}_{7}\right)$, es un eco en el ocho $\left(\mathrm{E}_{8}\right)$ y en el nueve (E9) "el ojo mágico juega a la escondida," se utiliza para desear a la grabadora la cualidad fantástica de reproducir algo diferente a lo grabado. El motivo $10\left(\mathrm{E}_{10}\right)$ toma parcialmente al primero $\left(\mathrm{E}_{1}\right)$ pero el contenido de la afirmación ontológica se cambia a uno de naturaleza antintelectual, "To que realmente soy es una mala parodia de Faulkner. Efectos fáciles." En la construcción de este motivo el autor recurre al referente, a su cultura literaria para obtener materiales de elaboración (la referencia a Faulkner).

Cuarto fragmento:

$\begin{array}{ll}(\text { Tema D) } & \text { ¿Dicta con un magnetófono o el whisky le sirve de } \\ \mathbf{E}_{11} & \text { cinta grabadora? } \\ \mathbf{E}_{12} & \text { ¿Se dice grabador magnetófono? Horacio dice magnetófono, } \\ & \text { se quedó asombrado al ver el artefacto, dijo: “Qué } \\ & \text { magnetófono, pibe." El manual dice grabador, los de Casa } \\ & \text { América deben saber. } \\ \mathbf{E}_{13} & \text { Misterio: por qué Manú compra todo, hasta los zapatos, en } \\ & \text { Casa América. Una fijación, una idiotez. }\end{array}$

El motivo $\mathrm{E}_{11}$ tiene todavía como base a Talita frente a la grabadora, pero la asociación está relacionada con la repetición del aparato y la locuacidad que produce la bebida. Es decir, se ha recurrido a la memoria y al referente para producir el fluir textual, y surge un elemento que servirá de "feedforward" al próximo motivo, que es la palabra "magnetófono." En el motivo $\mathrm{E}_{12}$ Talita discute si se dice magnetófono o grabador, y se produce un nuevo elemento que garantiza la continuidad textual, la frase "Casa América."

Es interesante notar que los trece motivos pueden agruparse a su vez, por el tema tratado, en cuatro temas de tres motivos cada uno (tema A,B,C,D), y uno $\left(\mathrm{E}_{10}\right)$ que sirve de puente, tal y como sucedería en una composición musical.

A través de los ejemplos anteriores se puede notar cómo Cortázar crea una forma textual discursiva comparable al fluir improvisativo del jazz, que basada en el libre juego de asociación permite obtener una visión más profunda de la realidad. La adaptación al análisis textual del modelo de improvisación musical de Jeff Pressing hace posible la observación de los aspectos que intervienen en la formación del "event cluster" o motivo textual y el proceso de transformación del texto y su significado, que garantiza la generación de variantes y, por tanto, el fluir discursivo, todo lo cual permite nuevas posibilidades de análisis de la obra cortazariana. 


\section{OBRAS CITADAS}

Cortázar, Julio. Rayuela. Barcelona: Editorial Seix Barral, S. A., 1986.

_. El perseguidor y otros relatos. Barcelona: Editorial Bruguera, S. A., 1980. . La vuelta al día en ochenta mundos. México: Siglo Veintiuno Editores, 1984.

Genover, Katheleen. Claves de una novelística existencial. Madrid: Editorial Playor, S. A., 1973.

Gioia, Ted. The Imperfect Art. Reflections on Jazz and Modern Culture. New York: Oxford University Press, 1988.

Harss, Luis. Los nuestros. Buenos Aires: Editorial Sudamericana, 1968.

Hudde, Hinrich. "El negro Fausto del jazz". Coloquio Internacional Lo lúdico y lo fantástico en la obra de Julio Cortázar. 2 vols. Ed. Centre de recherches Latino-Américaines. Madrid: Editorial Fundamentos, 1986. Vol. 2.

Picon, Evelyn. ¿̇Es Julio Cortázar un surrealista? Madrid: Editorial Gredos, 1975.

Pressing, Jeff. "Improvisation: Methods and Models." En John A. Sloboda, ed., Generative Processes in Music. New York: Oxford University Press, 1988.

Riposo, Joseph. "Improving Improvisation Through Understanding Hemisphericity." Jazz Educators Journal 21.2 (1989): 28+ 
